\title{
Derivations that enable the testing of fetal urine production as a method of fetal surveillance
}

\author{
Mats A. Fagerquist - Ulf O. Fagerquist • \\ Anders Odén - Sture G. Blomberg • \\ Lars-Ake Mattsson
}

Received: 16 May 2009/Accepted: 25 September 2009/Published online: 16 October 2009

(C) The Author(s) 2009. This article is published with open access at Springerlink.com

\begin{abstract}
Purpose To calculate the measurement error of the hourly fetal urine production rate (HFUPR) and evaluate the implication of different methods for measuring the HFUPR, i.e. ellipsoid versus sum-of-cylinders method.

Methods The calculation was based on sonographic documentation of the increased bladder volumes during the filling phase, the bladder volume measurement error and the number and time points of bladder image capture.

Results The probability of a false pathological reading was excluded $(0 \%)$ with the sum-of-cylinders method for gestational ages of $\geq 30$ weeks. With the ellipsoid method, the risk was higher. The maximum changes which could be
\end{abstract}

Electronic supplementary material The online version of this article (doi:10.1007/s00404-009-1242-6) contains supplementary material, which is available to authorized users.

M. A. Fagerquist $(\square)$

Department of Obstetrics and Gynaecology,

Näl, North Elfsborg County Hospital,

46185 Trollhättan, Sweden

e-mail: mats.fagerquist@vgregion.se; rosanna.roest@telia.com

U. O. Fagerquist

Edutec Inc., Littleton, MA, USA

A. Odén

Romelanda, Sweden

S. G. Blomberg

Department of Anaesthesiology,

Sahlgrenska University Hospital,

Gothenburg, Sweden

L.-A. Mattsson

Department of Obstetrics and Gynaecology,

Sahlgrenska University Hospital East,

Gothenburg, Sweden exclusively explained by measurement error were four to five times greater with the ellipsoid method compared with the sum-of-cylinders method.

Conclusions The present paper illustrates a careful evaluation of the HFUPR measurement error and the implications of using different ultrasound methods for bladder volume estimations.

Keywords Fetus · Urinary bladder - Ultrasonography · Organ volume $\cdot$ Reliability

\section{Introduction}

The skillful management and timing of delivery in high-risk pregnancies is important in order to avoid a poor perinatal outcome $[5,16]$. The challenge is the early identification of abnormal events. Different procedures to detect these abnormal events are available $[6,18]$. However, the fetal urine production rate is a parameter that has not been utilised in clinical practice, even though several studies demonstrate a reduction in blood flow in the fetal renal arteries and urine production rate in compromised fetuses [8-10, 14, 19].

When utilising the hourly fetal urine production rate (HFUPR) to detect abnormal events during pregnancy, reliable reference HFUPR values for normality are needed. Several attempts have been made to assess these values. However, previous ultrasound studies have presented widely varying reference ranges for fetuses of identical gestational ages. For example, at term, the presented values have varied from as much as $28,34,51$ and $71-125 \mathrm{~mL} / \mathrm{h}$ $[1,7,11,12,17]$. The huge variation was also present, regardless of whether the $2 \mathrm{D}$ or $3 \mathrm{D}$ technique was used, suggesting considerable measurement errors. Furthermore, detailed data on the total measurement error in these 


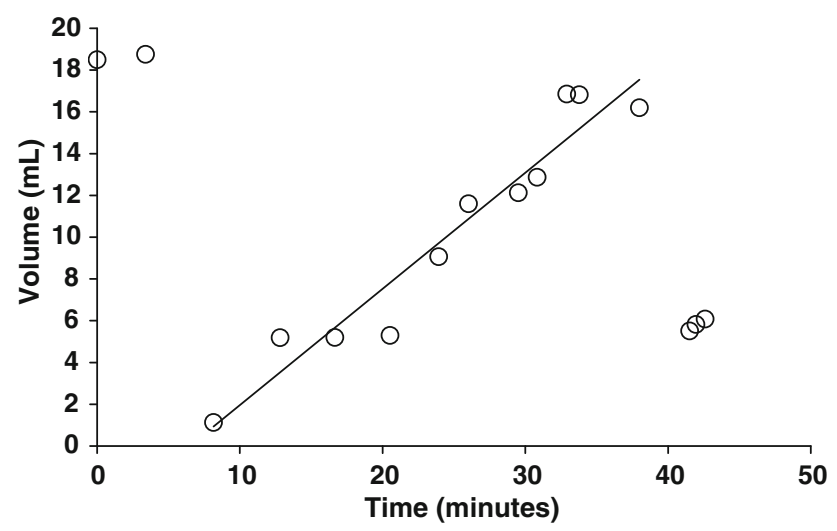

Fig. 1 Initially, the bladder was filled up to $19 \mathrm{ml}$ before emptying and a new filling phase began. For this 32-week fetus, the HFUPR of $33 \mathrm{~mL} / \mathrm{h}$ was estimated by regression function and extrapolation to a time span of $1 \mathrm{~h}$

studies are missing. This is unsatisfactory and a systematic investigation of the accuracy of HFUPR measurements is therefore needed.

When carrying out a systematic investigation of the accuracy of HFUPR measurements, it is important to recognize that the accuracy of HFUPR measurement in living fetuses cannot be assessed directly but only indirectly. The measurement error is made when assessing the volume of the bladder and only here. This measurement error will also be incorporated in the HFUPR estimation, which is based on a sequence of bladder images during the filling phase. There are some other factors that influence the HFUPR measurement error, i.e. the magnitude of the HFUPR and the number and time points of bladder image capture (Fig. 1).

In the current paper we illustrate the mathematical derivation of a formula to assess the HFUPR measurement error using these factors and the implication of using different methods for bladder volume. The objective of the paper was to enable responses to two clinically important questions: (1) what is the probability that the HFUPR will be falsely classified at the 2.5 th percentile or a lower value, even though the true HFUPR is at a higher percentile point? and (2) if we are to use the HFUPR in the evaluation of at-risk pregnancies by daily measurements, we need to know how much of the change can be explained exclusively by measurement error.

\section{Methods and subjects}

In spite of a constant volume, varying estimates will be found when assessing the volume of the fetal urinary bladder, due to measurement error [1-4]. This error was assumed to have a normal distribution and the standard deviation (SD) was therefore used as a measurement of estimation error (by us denoted $\mathrm{SD}_{\text {voluME}}$ ). This volume measurement error will be incorporated in the HFUPR estimation and the SD was consequently also utilized as the measurement of HFUPR estimation error (by us denoted $\mathrm{SD}_{\mathrm{HFUPR}}$ ).

To obtain a generally applicable formula for estimating

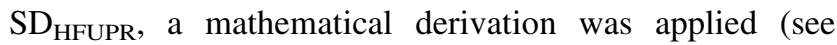
Statistics section). Although it is an original derivation it can be scrutinized by each statistician without difficulty. It is pure mathematics. In clinical practice, there are two fundamental questions that need to be answered: (1) what is the probability that the HFUPR will be falsely classified at the 2.5 th percentile or a lower value, even though the true HFUPR is at a higher percentile point? and (2) If we are to use the HFUPR in the evaluation of at-risk pregnancies by daily measurements, we need to know how much of the change can be explained exclusively by measurement error. These questions were answered by two supplementary formulas.

To illustrate the implication of the calculated $\mathrm{SD}_{\mathrm{HFUPR}}$, relevant values of HFUPR, $\mathrm{SD}_{\text {VOLUME }}$ number and time points of bladder image capture were required. The reference range of the HFUPR in an extensive 2D study (comprising 358 uncomplicated fetuses) was used and the 2.5th and 10th percentile point were calculated from a diagram in that study [15]. To date, detailed information on $\mathrm{SD}_{\text {VOLUME }}$ in living fetuses has been exclusively presented in studies of 2D ultrasound. To compare the implication of using different bladder volume methods (the ellipsoid or the sum-of-cylinders method), the calculated SD volumE in two other 2D studies was applied [2, 4].

\section{Statistics}

The measurement error when estimating the HFUPR

Assuming that $x_{1}, x_{2}, \ldots$ are the time points for bladder volume estimations during the filling phase (small letters for constants) and $Y_{1}, Y_{2}, \ldots$ are the estimated bladder volumes (capital letters for random variables), the HFUPR can be calculated as the coefficient of regression:

HFUPR $=\frac{\sum Y_{i}\left(x_{i}-\bar{x}\right)}{\sum\left(x_{i}-\bar{x}\right)^{2}}$.

This derivation of the coefficient of regression can be found in a number of statistical manuals.

The SD of the bladder volume measurements was assumed to be a linear function of volume.

$\mathrm{SD}_{\text {volume }}=a+b \times$ volume.

The volume $Y_{i}$ at the time point $x_{i}$ can be approximated as

$Y_{i}=x_{i} \times$ HFUPR 
and

$\mathrm{SD}_{\text {volume }}=a+b \times x_{i} \times$ HFUPR.

The different measurement errors, which are involved in each volume estimation during a filling phase, are regarded as statistically independent random variables.

When calculating $\mathrm{SD}_{\mathrm{HFUPR}}$, the corresponding variances are used. The variance in the HFUPR according to Eq. 1 equals the variance in $\frac{\sum Y_{i}\left(x_{i}-\bar{x}\right)}{\sum\left(x_{i}-\bar{x}\right)^{2}}$. The factors $\left(x_{i}-\bar{x}\right)$ and $\sum\left(x_{i}-\bar{x}\right)^{2}$ can be regarded as constants in this application.

Only the factor $\left(Y_{i}\right)$ must be taken into consideration and the variance $\left[S D\left(Y_{i}\right)\right]^{2}$ is used.

However, $Y_{i}$ is the estimated bladder volume and

$\mathrm{SD}\left(Y_{i}\right)=\mathrm{SD}_{\text {volume }}$

according to Eqs. 4 and $5, \quad\left[\operatorname{SD}\left(Y_{i}\right)\right]^{2}=\left(\operatorname{SD}_{\text {volume }}\right)^{2}=$ $\left(a+b \times x_{i} \times \text { HFUPR }\right)^{2}$.

Referring to Eq. 1, the variance in the measurement error when estimating the HFUPR is: $\left(\mathrm{SD}_{\text {HFUPR }}\right)^{2}=$ $\operatorname{Var}\left[\frac{\sum Y_{i} \cdot\left(x_{i}-\bar{x}\right)}{\sum\left(x_{i}-\bar{x}\right)^{2}}\right]$ and according to Eqs. 4 and 5:

$$
\begin{aligned}
\left(\mathrm{SD}_{\mathrm{HFUPR}}\right)^{2} & =\left\{\frac{\sum\left(a+b \times x_{i} \cdot \mathrm{HFUPR}\right)\left(x_{i}-\bar{x}\right)}{\left[\sum\left(x_{i}-\bar{x}\right)^{2}\right]}\right\}^{2} \\
& =\frac{\sum\left(a+b \times x_{i} \times \mathrm{HFUPR}\right)^{2}\left(x_{i}-\bar{x}\right)^{2}}{\left[\sum\left(x_{i}-\bar{x}\right)^{2}\right]^{2}}
\end{aligned}
$$

and

$\mathrm{SD}_{\mathrm{HFUPR}}=\frac{\left.\left[\sum\left(a+b \times x_{i} \times \mathrm{HFUPR}\right)^{2}\left(x_{i}-\bar{x}\right)^{2}\right)\right]^{1 / 2}}{\sum\left(x_{i}-\bar{x}\right)^{2}}$.

Using the valid values for the constants $a$ and $b$, the mean time for bladder image documentation $\bar{x}$ and the time points when images were captured, the $\mathrm{SD}_{\mathrm{HFUPR}}$ turned out to be an approximately linear function of the HFUPR and can be expressed as:

$\mathrm{SD}_{\mathrm{HFUPR}}=c+d \times$ HFUPR.

The values of the constants $c$ and $d$ depend on the $\mathrm{SD}_{\text {VOLUME }}$ and time points for bladder image capture.

The statistical derivations relating to the two clinical examples

1. What is the maximum change in the HFUPR that could be caused exclusively by measurement errors?

Assuming that the actual HFUPR $=x$ on two occasions, what is the probability that the difference between these two determinations (in spite of a constant HFUPR) is at least as extreme as a quantity $\Delta$ ? Assuming that $\Phi$ is the distribution function of the standardized normal distribution, the probability of assessing an HFUPR, which is a magnitude of $\Delta$ less than 0 , is:

$\Phi\left(\frac{0-\Delta}{\mathrm{SD}}\right)$.

However, in this example, $\mathrm{SD}=\mathrm{SD}_{\mathrm{HFUPR}} \times \sqrt{2}$, whereas $\sqrt{2}$ depends on the evaluation of a difference and $\mathrm{SD}_{\mathrm{HFUPR}}=c+d \times x$ according to (7). The probability that the difference between two determinations is at least as extreme as a quantity $\Delta$ is: $2 \times \Phi\left(\frac{-|\Delta|}{(c+d \times x) \sqrt{2}}\right)$. For example, the probability attains a value of $5 \%$ if

$\Delta= \pm 1.96\lfloor(c+d \times x) \sqrt{2}\rfloor$.

2. What is the probability that the HFUPR will be falsely classified at the 2.5 th percentile or a lower value, whereas the true HFUPR is at the 10th percentile point?

When the true HFUPR is exactly at the 10th percentile point $\left(x_{10}\right)$, the measured HFUPR will have a normal distribution with the mean value $\left(x_{10}\right)$. In line with the discussion in the previous example, the difference is $x_{2.5}-x_{10}$ and the standard deviation $\mathrm{SD}=\mathrm{SD}_{\mathrm{HFUPR}}=$ $c+d \times x_{10}$. The probability of obtaining an HFUPR value less than the 2.5 th percentile can be calculated as

$\Phi\left(\frac{x_{2.5}-x_{10}}{c+d \times x_{10}}\right)$.

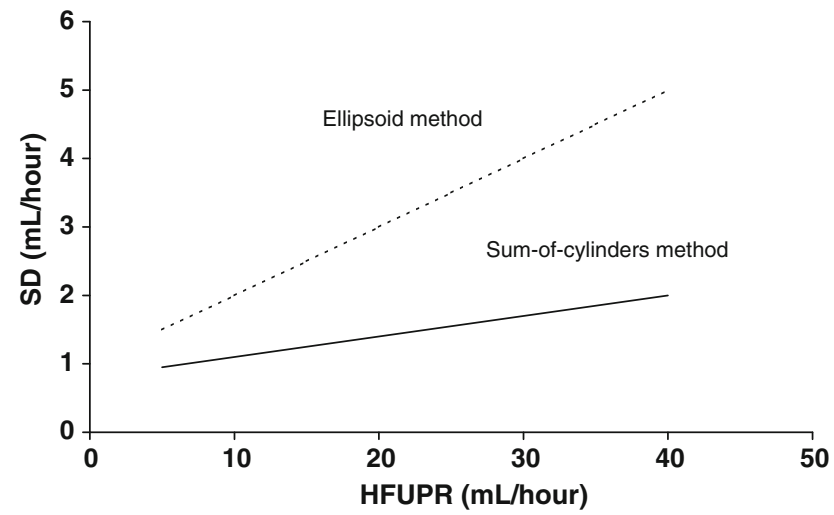

Fig. 2 This calculation of the HFUPR measurement error $\left(\mathrm{SD}_{\mathrm{HFUPR}}\right)$ was based on images captured at five, 10, 15, 20, 25 and 30 min after an emptying phase, when applying the ellipsoid and the sum-of-cylinders method (different $\mathrm{SD}_{\text {VOLUME }}$ ). The $\mathrm{SD}_{\mathrm{HFUPR}}$ ranged from 31 to $12 \%$ for the ellipsoid method and from 20 to $5 \%$ for the sum-of-cylinders method for HFUPRs of $5-40 \mathrm{~mL} / \mathrm{h}$ 
Table 1 The influence of different numbers and times of image capture is illustrated for some situations, when calculating the $\mathrm{SD}_{\text {HFUPR }}\left(\mathrm{SD}_{\text {HFUPR }}=c+d \times\right.$ HFUPR $)$

\begin{tabular}{lll}
\hline $\begin{array}{l}\text { Number and time } \\
\text { points of volume } \\
\text { estimations }\end{array}$ & $\mathrm{SD}_{\text {HFUPR }}$ & \\
\cline { 2 - 3 } & Ellipsoid method & $\begin{array}{l}\text { Sum-of-cylinders } \\
\text { method }\end{array}$ \\
\hline
\end{tabular}

6 (time points: $1,2, \quad 1.0+0.10 \times$ HFUPR $0.8+0.03 \times$ HFUPR $3,4,5,6)$

5 (time points: $1,2, \quad 1.1+0.12 \times$ HFUPR $0.9+0.03 \times$ HFUPR $3,4,6)$

4 (time points: $1,2, \quad 1.9+0.13 \times$ HFUPR $1.6+0.03 \times$ HFUPR $3,4)$

3 (time points: $1,2,2.0+0.14 \times$ HFUPR $1.6+0.04 \times$ HFUPR 4)

2 (time points: 1,3$) \quad 3.0+0.15 \times$ HFUPR $2.5+0.04 \times$ HFUPR 2 (time points: 1,6$) 1.1+0.12 \times$ HFUPR $1.0+0.03 \times$ HFUPR

The alternative image capture times (time points 1-6) were five, 10, $15,20,25$ and $30 \mathrm{~min}$ after an emptying phase. It can be seen that $\mathrm{SD}_{\text {HFUPR }}$ is based on whether the time intervals between image capture are 10 or 25 min (rows 5 and 6). Moreover, the calculated $\mathrm{SD}_{\mathrm{HFUPR}}$ is dependent on the volume estimation method that was used

\section{Results}

The SD for the estimated HFUPR ( $\left.\mathrm{SD}_{\mathrm{HFUPR}}\right)$ depends on the method of bladder volume estimation ( $\mathrm{SD}_{\mathrm{VOLUME}}$ ), the magnitude of the HFUPR and the number and time points of bladder image capture. The derivation was presented in Formulas 6 and 7 in the Statistics section. The new constants $c$ and $d$ in Eq. 7 are crucial for the further derivations (Fig. 2; Table 1).

The probability of falsely reading the 10th percentile point as a pathological value (i.e. below the 2.5 th percentile point) was excluded (0\%) with the sum-of-cylinders method for gestational ages of $\geq 30$ weeks (see Formula 10, Statistics section). With the ellipsoid method, the risk was higher (Table 2).

Using Formula 9 (Statistics section), the maximum changes which might be exclusively explained by measurement error were four to five times greater (25-30\%) with the ellipsoid method compared with the sum-of-cylinders method $(6 \%)$ (Table 3$)$.

\section{Discussion}

A starting point for the present paper is the linear relationship between bladder volume and the measurement error: $\mathrm{SD}_{\text {volume }}=a+b \times$ volume. This relationship has been thoroughly documented in three previous studies $[2,3,4]$. When all the cases in these studies are included, the distribution of the SD and residuals supports a linear relationship, which is a prerequisite for using a linear regression function [13] (Figs. 3 and 4).

The main finding in the present paper is a general formula for calculating the $\mathrm{SD}_{\mathrm{HFUPR}}$, which is valid when using $2 \mathrm{D}$ ultrasound. As we understand it, this measurement error can only be assessed indirectly by this kind of calculation. The measurement error is made when assessing the volume of
Table 2 Shows the probability of false HFUPR readings at the 2.5 th percentile point or a lower level, even though the true HFUPR was at the 10th percentile point
The ellipsoid and the sumof-cylinders methods were compared (different

$\mathrm{SD}_{\text {VOLume }}$ ). For the sum-ofcylinders method, the number of false readings was $<3 \%$ for fetuses of $>24$ weeks

\begin{tabular}{|c|c|c|c|c|c|}
\hline \multirow{2}{*}{$\begin{array}{l}\text { Gestational age } \\
\text { (weeks) }\end{array}$} & \multirow{2}{*}{$\begin{array}{l}\text { Mean } \\
(\mathrm{mL} / \mathrm{h})\end{array}$} & \multirow{2}{*}{$\begin{array}{l}\text { 10th percentile } \\
(\mathrm{mL} / \mathrm{h})\end{array}$} & \multirow{2}{*}{$\begin{array}{l}\text { 2.5th percentile } \\
(\mathrm{mL} / \mathrm{h})\end{array}$} & \multicolumn{2}{|c|}{ Probability (per cent) } \\
\hline & & & & $\begin{array}{l}\text { Ellipsoid } \\
\text { method }\end{array}$ & $\begin{array}{l}\text { Sum-of-cylinders } \\
\text { method }\end{array}$ \\
\hline 22 & 7.4 & 4.3 & 2.7 & 13 & 5 \\
\hline 23 & 8.4 & 5.1 & 3.3 & 12 & 4 \\
\hline 24 & 9.4 & 5.8 & 3.9 & 11 & 3 \\
\hline 25 & 10.4 & 6.6 & 4.5 & 10 & 2 \\
\hline 26 & 11.5 & 7.3 & 5.1 & 10 & 2 \\
\hline 27 & 12.2 & 8.0 & 5.7 & 10 & 2 \\
\hline 28 & 12.9 & 8.6 & 6.3 & 10 & 2 \\
\hline 29 & 15.1 & 9.9 & 7.1 & 7 & 1 \\
\hline 30 & 17.4 & 11.3 & 8.0 & 6 & 0 \\
\hline 31 & 21.0 & 12.7 & 8.3 & 2 & 0 \\
\hline 32 & 24.7 & 14.7 & 9.3 & 1 & 0 \\
\hline 33 & 27.8 & 16.8 & 11.0 & 1 & 0 \\
\hline 34 & 30.9 & 19.0 & 12.7 & 1 & 0 \\
\hline 35 & 35.3 & 21.9 & 14.8 & 1 & 0 \\
\hline 36 & 39.7 & 24.9 & 17.1 & 2 & 0 \\
\hline 37 & 41.0 & 26.5 & 18.7 & 2 & 0 \\
\hline 38 & 42.4 & 28.0 & 20.4 & 2 & 0 \\
\hline
\end{tabular}


Table 3 The magnitude of change in the estimated HFUPR from the initial 10th percentile point, which might be caused exclusively by measurement error, was calculated
Values higher than these may also be produced by measurement errors, but the probability was less than $5 \%$.

The change, which might be due exclusively to measurement error, is just a quarter when using the sum-of-cylinders method vs. the ellipsoid method

\begin{tabular}{llll}
\hline $\begin{array}{l}\text { Gestational age } \\
\text { (weeks) }\end{array}$ & $\begin{array}{l}\text { 10th percentile } \\
(\mathrm{mL} / \mathrm{h})\end{array}$ & \multicolumn{2}{l}{ Measurement error $(\mathrm{mL} / \mathrm{h})$} \\
\cline { 3 - 4 } & & Ellipsoid method & Sum-of-cylinders method \\
\hline 22 & 4.3 & 1.2 & 0.3 \\
23 & 5.1 & 1.3 & 0.3 \\
24 & 5.8 & 1.6 & 0.4 \\
25 & 6.6 & 1.7 & 0.4 \\
26 & 7.3 & 1.9 & 0.4 \\
27 & 8.0 & 2.1 & 0.5 \\
28 & 8.6 & 2.3 & 0.5 \\
29 & 9.9 & 2.6 & 0.6 \\
30 & 11.3 & 3.0 & 0.7 \\
31 & 12.7 & 3.4 & 0.8 \\
32 & 14.7 & 3.9 & 0.9 \\
33 & 16.8 & 4.4 & 1.0 \\
34 & 19.0 & 5.0 & 1.1 \\
35 & 21.9 & 5.8 & 1.3 \\
36 & 24.9 & 6.6 & 1.5 \\
37 & 26.5 & 7.7 & 1.6 \\
38 & 28.0 & 7.4 & 1.7 \\
\hline
\end{tabular}

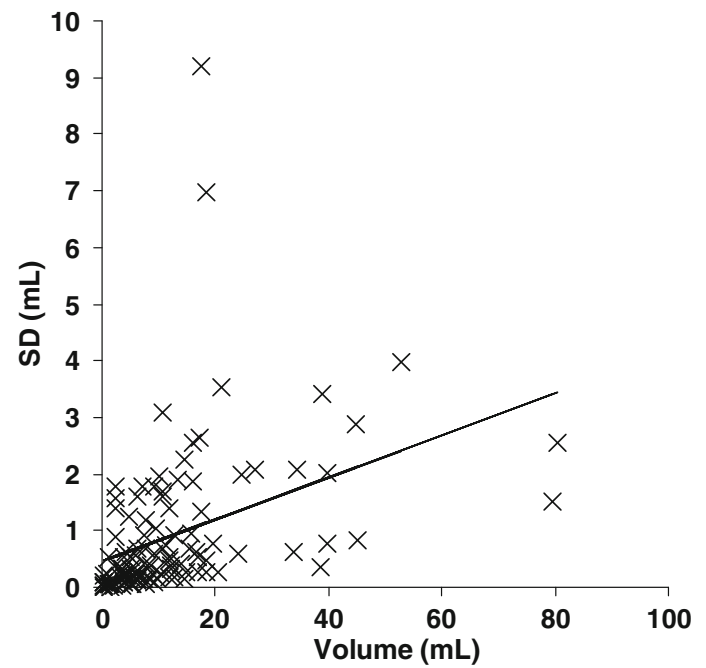

Fig. 3 The SD was calculated when estimating the bladder volume of 120 fetuses. Different methods were used, which gave rise to 222 relationships between SD and bladder volume. The maximum and minimum bladder volumes were 80.5 and $0.1 \mathrm{~mL}$, respectively. The distribution of the SDs supports a linear relationship

the bladder-and only then. When the linear relationship between the bladder volume and measurement error is taken into consideration, there is a specific $\mathrm{SD}_{\mathrm{VOLUME}}$ related to each estimated volume. The magnitude of the constants $a$ and $b$ depends on the volume assessment method that is used, e.g. 2D ultrasound (ellipsoid and sum-of-cylinders method). The $a$ and $b$ for the ellipsoid method are 0.36516 and 0.09978, whereas they are 0.29911 and 0.02788 for the sum-of-cylinders method. For 3D ultrasound, the

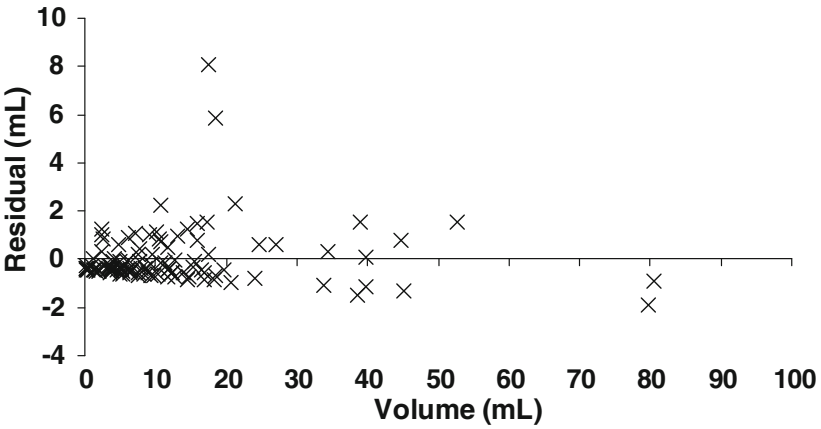

Fig. 4 The distribution of the residuals supports a linear relationship between the SD and bladder volume based on 222 relationships between the SD and bladder volume. The maximum and minimum of the residuals were 8.2 and $-1.9 \mathrm{~mL}$, respectively. The mean was 0.00 $\mathrm{mL}$ and the median $-0.37 \mathrm{~mL}$

relationship between $\mathrm{SD}_{\text {VOLUME }}$ and the estimated volume is as yet unknown. However, the current paper illustrates the usefulness of this relationship and the implication of using different 2D methods for volume estimation.

When utilizing the HFUPR for fetal surveillance, we need to know whether the estimated HUFPR is pathologically low, i.e. below the 2.5 th percentile point. We therefore need to answer the question: What is the risk of false readings at the 2.5 th percentile point, for example, even though the true HFUPR is at a higher percentile point? (see Formula 10 in Statistics).

Furthermore, we need to answer the question: How much of an observed HFUPR change (for example, during daily controls) can be explained exclusively by measurement error? (see Formula 9 in Statistics). 
In some previous ultrasound studies, the quality of bladder volume as well as HFUPR measurements has been addressed [7, 11, 12, 17]. These studies lack detailed measurement error data and are not sufficient as a basis for HFUPR evaluation. With the assistance of our mathematical derivations of the $\mathrm{SD}_{\mathrm{HFUPR}}$, however, the answers to the two questions are within reach. Only three data are needed to obtain the $\mathrm{SD}_{\mathrm{HFUPR}}$ : (1) the relationship between bladder volume and $\mathrm{SD}_{\text {VOLUME }}$ for the estimation method that is used (determines the constants $a$ and $b$ ), (2) the time points of image capture and (3) the estimated HFUPR. According to Statistics, there is also a linear relationship between $\mathrm{SD}_{\mathrm{HFUPR}}$ and the HFUPR. This relationship $\mathrm{SD}_{\mathrm{HFUPR}}=c+d \times H F U P R$ can be utilised for further calculations of the constants $c$ and $d$, which provides the answers to the aforementioned questions. Moreover, the implication of using different methods for bladder volume is illustrated.

\section{Conclusions}

When $\mathrm{SD}_{\mathrm{HFUPR}}$, the magnitude of the HFUPR and the time points of bladder image capture are taken into account, there is a probability of falsely classifying the HFUPR at the 2.5th percentile or a lower value, even though the true HFUPR at the 10th percentile point may be estimated. Moreover, when evaluating at-risk pregnancies by daily HFUPR measurements, we can assess how much of the change can be explained exclusively by measurement error.

Acknowledgments We would like to thank Ingemar Kjellmer, Professor at the Department of Paediatrics, Queen Silvia's Children's Hospital, Goteborg. Thank you for your support and enthusiasm for the subject. This study was supported by grants from the North Elvsborg Foundation for Medical Development and Research and the Goteborg Medical Society.

\section{Conflict of interest statement None.}

Open Access This article is distributed under the terms of the Creative Commons Attribution Noncommercial License which permits any noncommercial use, distribution, and reproduction in any medium, provided the original author(s) and source are credited.

\section{References}

1. Campbell S, Wladimiroff JW, Dewhurst CJ (1973) The antenatal measurement of fetal urine production. J Obstet Gynaecol $\mathrm{Br}$ Commonw 80:680-686

2. Fagerquist M, Fagerquist U, Oden A, Blomberg SG (2001) Fetal urine production and accuracy when estimating fetal urinary bladder volume. Ultrasound Obstet Gynecol 17:132-139

3. Fagerquist M, Fagerquist U, Steyskal H, Oden A, Blomberg SG (2002) Accuracy in estimating fetal urinary bladder volume using a modified ultrasound technique. Ultrasound Obstet Gynecol 19:371-379
4. Fagerquist M, Fagerquist U, Oden A, Blomberg SG (2003) Estimation of fetal urinary bladder volume using the sum-ofcylinders method vs. the ellipsoid formula. Ultrasound Obstet Gynecol 22:67-73

5. Ferrazzi E, Bozzo M, Rigano S, Bellotti M, Morabito A, Pardi G, Battaglia FC, Galan HL (2002) Temporal sequence of abnormal Doppler changes in the peripheral and central circulatory systems of the severely growth-restricted fetus. Ultrasound Obstet Gynecol 19:140-146

6. Hajek Z, Srp B, Haddad el R, Drbohlav P, Parizek A, Liska K, Paskova A, Zvarova J, Simeckova A (2005) Analysis of present diagnostic methods of intrapartum fetal hypoxia. Ceska Gynekol 70:22-26

7. Lee SM, Park SK, Shim SS, Jun JK, Park JS, Syn HC (2007) Measurement of fetal urine production by three-dimensional ultrasonography in normal pregnancy. Ultrasound Obstet Gynecol 30:281-286

8. Mikovic Z, Mandic V, Djukic M, Egic A, Filimonovic D, Cerovic N, Popovac M (2003) Longitudinal analysis of arterial Doppler parameters in growth retarded fetuses. Srp Arh Celok Lek 131:21-25

9. Miura H (1991) Evaluation of fetal renal arterial blood flow waveforms with pulsed Doppler flowmetry and the correlation to estimated fetal body weight, fetal urine production rate and amniotic fluid volume. Nippon Sanka Fujinka Gakkai Zasshi 43:1647-1652

10. Nicolaides KH, Peters MT, Vyas S, Rabinowitz R, Rosen DJ, Campbell S (1990) Relation of rate of urine production to oxygen tension in small-for-gestational-age fetuses. Am J Obstet Gynecol $162: 387-391$

11. Rabinowitz R, Peters MT, Vyas S, Campbell S, Nicolaides KH (1989) Measurement of fetal urine production in normal pregnancy by real-time ultrasonography. Am J Obstet Gynecol 161:1264-1266

12. Shin T, Koyanagi T, Hara K, Kubota S, Nakano H (1987) Development of urine production and urination in the human fetus assessed by real-time ultrasound. Asia Oceania J Obstet Gynaecol 13:473-479

13. Skrepnek GH (2005) Regression Methods in the Empiric Analysis of Health Care Data. J Manag Care Pharm 11(3):240-251

14. Stigter RH, Mulder EJ, Bruinse HW, Visser GH (2001) Doppler studies on the fetal renal artery in the severely growth-restricted fetus. Ultrasound Obstet Gynecol 18:141-145

15. Takeuchi H, Koyanagi T, Yoshizato T, Takashima T, Satoh S, Nakano H (1994) Fetal urine production at different gestational ages: correlation to various compromised fetuses in utero. Early Hum Dev 40:1-11

16. Thornton JG, Hornbuckle J, Vail A, Spiegelhalter DJ, Levene M (2004) Infant wellbeing at 2 years of age in the Growth Restriction Intervention Trial (GRIT): multicentred randomised controlled trial. Lancet 364:513-520

17. Touboul C, Boulvain M, Picone O, Levaillant JM, Frydman R, Senat MV (2008) Normal fetal urine production rate estimated with 3-dimensional ultrasonography using the rotational technique (virtual organ computer-aided analysis). Am J Obstet Gynecol 199(1):57

18. Turan S, Turan OM, Berg C, Moyano D, Bhide A, Bower S, Thilaganathan B, Gembruch U, Nicolaides K, Harman C, Baschat AA (2007) Computerized fetal heart rate analysis, Doppler ultrasound and biophysical profile score in the prediction of acidbase status of growth-restricted fetuses. Ultrasound Obstet Gynecol 30:750-756

19. Vyas S, Nicolaides KH, Campbell S (1989) Renal artery flowvelocity waveforms in normal and hypoxemic fetuses. Am J Obstet Gynecol 161:168-172 